\section{KẾT LUẬN}

Kết quả nghiên cứu độc tính bán trường diễn theo đường uống của viên nang cứng Fucolen cho thây Fucolen liều tương đương liêu dự kiến lâm sàng $(0,48$ viên $/ \mathrm{kg} / \mathrm{ngày})$ không làm ảnh hưởng xấu đến tình trạng chung, trọng lượng của chuột cống trắng tằng so với trước nghiên cứu, sự khác biệt có ý nghĩa thông kê so với lô chứng sau 12 tuân nghiên cứu. Không gây tổn thương tế bào gan (hoạt độ AST, ALT trong máu chuột cống trắng), khống làm thay đổi kết quả nồng độ bilirubin toàn phân, cholesterol toàn phân và albumin trong máu chuột cống trắng so với lô chứng. Không có sự khác biệt rõ ràng về cấu trúc vi thể gan và thận khi so sánh giữa lô trị và lô chứng.

\section{TÀI LIẸU THAM KHẢO}

1. Cuong H.D., Thuy T.T.T., Huong T.T., và cộng sự. Structure and hypolipidaemic activity of fucoidan extracted from brown seaweed Sargassum henslowianum. Nat. Prod. Res. 2015; 29:411-415.

2. Malve H. Exploring the ocean for new drug developments: Marine pharmacology. J. Pharm. Bioallied Sci. 2016; 8:83-91.

3. Kinghorn A.D., Chin Y.W., Swanson S.M. Discovery of natural product anticancer agents from biodiverse organisms. Curr. Opin. Drug Discov. Dev. 2009;12: 189-196.

4. Sanjeewa K.K.A., Kim E.A., Son K.T., và công sư. Bioactive properties and potentials cosmeceutical applications of phlorotannins isolated from brown seaweeds: A review. J. Photochem. Photobiol. B-Biol. 2016; 162:100-105.

5. Cunha L., Grenha A. Sulfated Seaweed Polysaccharides as Multifunctional Materials in Drug Delivery Applications. Mar. Drugs. 2016; 14:42.

6. Sanjeewa K.K.A., Kim E.A., Son K. T. Bioactive properties and potentials cosmeceutica applications of phlorotannins isolated from brown seaweeds: A review. J. Photochem. Photobiol. BBiol. 2016; 162:100-105.

7. Bộ Y tế. Quy chế Đánh giá tính an toàn và hiệu lực thuốc Cố truyền. Quyết định số 371/BYT-QĐĐ ngày 12/3/1996. 1996.

\title{
NGHIÊN CỨU ĐĂC ĐIỂM LÂM SÀNG, CÂN LÂM SÀNG UNG THƯ HẠ HỌNG - THANH QUẢN GIAI ĐOẠN III, IVA-B TẠI BỆNH VIỆN UNG BƯỚU NGHÊ AN NĂM 2020
}

\section{TÓM TẮT}

Ung thư hạ họng - thanh quản (UTHH-TQ) là loại ung thư tương đối phổ biến, chiếm khoảng $6 \%$ trong các loại ung thư vùng đầu cổ. Bệnh không những ảnh hưởng trầm trong đến các chức năng thở, nuốt và nói mà còn nguy hại đến tính mạng. Nếu được phát hiện sớm và điêu trị kịp thời có thể ha thấp tỉ lệ tử vong một cách đáng kê. Mục tiêu: Mô tả một số đặc điểm lâm sàng, mô bênh hơc UTHH-TQ giai đoạn III, IVA-B. Đánh giá hình thái tổn thương UTHH-TQ qua nội soi. Đối tượng và phương pháp nghiên cứu: 53 người bệnh và 48 hồ sơ bệnh án UTHH-TQ giai đoạn III, IVA-B tại bênh viện Ung bướu Nghệ An từ tháng 01/2020 đến hết tháng 12/2020. Phương pháp nghiên cứu: Thu thập số liệu thông tin thứ cấp trên 48 bênh án, khám và hỏi trên 53 người bênh. Kết quả: Chỉ số toàn trang (PS) chủ yếu $P S=1(64,4 \%)$; rối loạn nuốt $93 / 101(92,1 \%)$, nổi hach cổ 74/101 $(73,3 \%)$, khàn tiếng $21 / 101(20,8 \%)$. Giai đoạn bệnh chủ yếu giai đoạn IV 70/101 (79,3\%). Mô bệnh học:

${ }^{1}$ Bệnh viện Ung bướu Nghệ An

Bê̂nh viện $K$

Chiu trách nhiêm chính: Thái Đình Hiếu

Email: Thaihieutbmu@gmail.com

Ngày nhân bài: 15.01.2021

Ngày phản biên khoa học: 15.3.2021

Ngày duyệt bài: 25.3.2021
Thái Đình Hiếu', Nguyễn Tiến Quang ${ }^{2}$

$100 \%$ ung thư biểu mô tế bào vảy có độ mô học II và III. Ung thư hạ họng - thanh quản chủ yếu xuất phát từ xoang lê $82 / 101(81,2 \%)$. Thể sùi gặp nhiều nhất $70 / 101(69,3 \%)$.

Tư khóa: Ung thư ha họng - thanh quản; đăc điểm lâm sàng, cận lâm sàng.

\section{SUMMARY}

RESEARCH CLINICAL AND SUBCLINICAL CHARACTERISTICS OF STAGE III, IVA-B HYPOPHARYNGEAL AND LARYNGEAL CANCER IN NGHE AN ONCOLOGY HOSPITAL IN 2020

Hypopharyngeal and laryngeal cancer is a common cancer, accounting for approximately $6 \%$ of head and neck carcinoma. The disease is not only seriously affecting to the functions of breathing, swallowing and speaking but also life-threatening. If the disease is detected and treated early, it can reduce significantly the incidence of mortality. Objective: To describe some clinical characteristics, histopathology of stage III, IVA-B hypopharyngeal and laryngeal cancer. To assess morphological leisions of hypopharyngeal and laryngeal cancer by endoscopy. Patients and methods: 101 patients with stage III, IVA-B hypopharyngeal and laryngeal cancer recieved neoadjuvant chemotherapy or chemoradiotherapy in Nghe An Oncology hospital from January 2020 to December 2020. Method: Data collection on 48 medical records and 53 patients. Results: $P S=1$ is 
more in favor of performance status; Dysphagia $92.1 \%$, cervical lymph node metastasis $73.3 \%$, hoarseness $20.8 \%$; Stage IV $79.3 \%$. $100 \%$ SCC grade II, III. The sit initial of pyriform sinus $81.2 \%$. The exophytic form $69.3 \%$.

Keywords: Hypopharyngeal and laryngeal cancer; clinical and subclinical characteristics.

\section{I. ĐĂT VẤN ĐỀ}

Ung thư ha hong thanh quản (UTHH-TQ) là bênh ác tính có tổn thương xuất phát từ lớp biểu mô vảy của niêm mạc bao phủ hạ họng - thanh quản. Ở giai đoạn sớm tổn thương khu trú ở một vị trí, sang giai đoạn muộn có thể xâm lấn từ hạ hong xuống thanh quản hoặc ngược lại, khó phân định xuất phát điểm. Mổ bệnh học của hai vị trí này chủ yếu là ung thư biểu mổ tế bào vảy. Hiện nay các tác giả đều gọi chung là UTHH-TQ. Theo Globocan 2020, ung thư thanh quản đứng thứ 20 với số ca mới mắc là 184615 và số ca tứ vong 99840 trong khi đó UTHH đứng thứ 25 với số ca mới mắc 84254 và 38599 ca tử vong. Tại Việt Nam, theo thống kê năm 2020, ung thư thanh quản đứng thứ 19 với số ca mới mắc 2021 và số ca tử vong là 1109 . UTHH đứng thứ 17 với số ca mới mắc 2356 và số ca tử vong 1246.

Trong bệnh UTHH-TQ, triệu chứng khởi đầu thường âm thầm, phần lớn người bệnh nhập viện khi đã ở giai đoạn muộn (III, IV). Ở giai đoạn còn phẫu thuật được, phương pháp cắt hạ họng thanh quản toàn phần hoăcc một phần cho kết quả tương đối khả quan. Ở giai đoạn III, IVA-B với người bệnh không phẫu thuật được, hóa chất bố trợ trước và hóa xa trị đồng thời được sử dụng là phương pháp điều trị cơ bản. Phát hiện sớm triệu chứng lâm sàng, cận lâm sàng sẽ quyết định phác đồ điều trị và ảnh hưởng đến kết quả điều trị cũng như chất lượng sống của người bệnh. Trên thế giới và tại Việt Nam đã có một số tác giả nghiên cứu về đặc điểm lâm sàng, cận lâm sàng của UTHH-TQ. Tuy nhiên chưa có nhiều công trình nghiên cứu đưa ra số liệu cụ thể về đặc điểm lâm sàng và cận lâm sàng của UTHH-TQ và tại bệnh viện Ung bướu Nghệ An cũng chưa có đề tài nào đi sâu nghiên cứu lĩnh vực này. Để góp thêm một mảnh ghép vào bức tranh toàn cảnh UTHH-TQ, đề tài "Nghiên cứu đặc điểm lâm sàng, cận lâm sàng ung thư hạ họng - thanh quản giai đoạn III, IVAB tại bệnh viện Ung bướu Nghệ An năm 2020" được tiến hành. Mục tiêu nghiên cứu

1. Mô tả một số đặc điểm lâm sàng, mô bênh hoc UTHH-TQ giai đoạn III, IVA-B tại bệnh viện Ung bướu Nghê An từ 01/01/2020 đến 31/12/2020.

2. Mô tả hinh thái tôn thương UTHH-TQ qua nội soi.

\section{II. ĐỐI TƯỢNG VÀ PHƯƠNG PHÁP NGHIÊN CỨU}

1. Thời gian và địa điểm nghiên cứu

- Thời gian: Từ tháng 1 - tháng 12 năm 2020.

- Địa điểm: Tại Bệnh viện Ung bướu Nghệ An.

\section{2. Đối tượng nghiền cứu}

- Tiêu chuẩn lựa chọn đối tượng nghiên cứu:

+ Bệnh nhân được chẩn đoán UTHH-TQ lần đầu giai đoạn III, IVA-B theo phân loại của hiệp hội Ung thư Mỹ (AJCC) 2017.

+ Không mắc ung thư thứ hai.

+ Có hồ sơ bệnh án lưu trữ đầy đủ.

\section{Phương pháp nghiên cứu}

- Thiết kế nghiên cứu: Mô tả cắt ngang kết hợp hồi cứu hồ sơ bệnh án.

\section{Chon mấu và cỡ mẫu}

Chọn toàn bộ bệnh nhân đủ tiêu chuẩn trong thời gian nghiên cứu tại Bệnh viện được 101 bênh nhân.

5. Công cụ và kỹ thuật thu thập số liệu

- Công cụ: Bệnh án nghiên cứu thiết kễ sẵn.

- Thu thập số liệu:

+ Hồi cứu các hồ sơ bệnh án: 48 bệnh nhân

+ Hỏi và khám trực tiếp những người bệnh hiện còn điều trị tại bệnh viện kết hợp thu thập thông tin từ hồ sơ bệnh án: 53 bệnh nhân.

\section{Khống chế sai số}

- Tất cả người bệnh được lưu trữ đầy đủ bằng bệnh án nghiên cứu và trên máy tính.

Điều tra viên được tập huấn và sử dụng bệnh án nghiên cứu để phỏng vấn.

7. Xử lý số liệu: Các số liệu thu thập được nhập và xử lý bằng phần mềm thống kề $Y$ học SPSS 20.0, Excel và Word.

8. Đạo đức nghiên cứu. Nghiên cứu được thông qua đề cương bởi Hội đồng khoa học Bệh viện Ung bướu Nghệ An trước khi tiến hành nghiên cứu. Thông tin của bệnh nhân tham gia nghiên cứu đảm bảo giữ kín và chỉ dùng cho mục đích nghiên cứu.

\section{KẾT QUẢ NGHIÊN CứU}

Bảng 4.1. Đặc điểm lâm sàng và mô bệnh học

\begin{tabular}{|c|c|c|}
\hline & $\begin{array}{c}\text { Số } \\
\text { lượng }\end{array}$ & $\begin{array}{c}\text { Tỷ lệ } \\
\text { \%ọ }\end{array}$ \\
\hline $\begin{array}{c}\text { Chỉ số toàn tranng lúc } \\
\text { vào viện }\end{array}$ & & \\
0 & 13 & 12,9 \\
1 & 65 & 64,4 \\
2 & 22 & 21,8 \\
3 & 1 & 1 \\
4 & 0 & 0 \\
\hline Triệu chứng cơ năng & & \\
\hline
\end{tabular}




\begin{tabular}{|c|c|c|}
\hline Rối loạn nuốt & 93 & 92,1 \\
Nổi hạch cổ & 74 & 73,3 \\
Khàn tiếng & 21 & 20,8 \\
Ho khan & 18 & 17,8 \\
Khó thở & 12 & 11,9 \\
\hline Mô bệnh học & & \\
Độ I & 0 & 0 \\
Độ II & 92 & 91 \\
Độ III & 9 & 9 \\
Độ IV & 0 & 0 \\
\hline
\end{tabular}

Nhân xét: Kết quả bảng trên cho thấy hơn một nửa số người bệnh, vào viện vì rối loạn chức năng nuốt và nổi hạch cổ; chỉ số toàn trạng (PS) thường găp ở mức $P S=1$. Tất cả người bênh có mô bênh học là ung thư biểu mô tế bào vảy (SCC) trong đó chỉ gặp ở độ II và III.

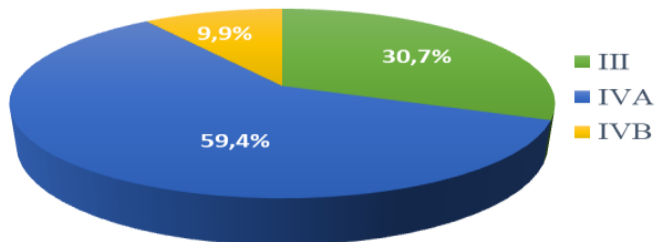

Giai đoạn bệnh

Biểu đồ 4.1. Phân bố theo giai đoạn bệh

Nhân xét: Kết quả từ biêu đồ trển cho thấy phân lớn bệnh nhân trong nghiên cứu ở giai đoạn IVA.

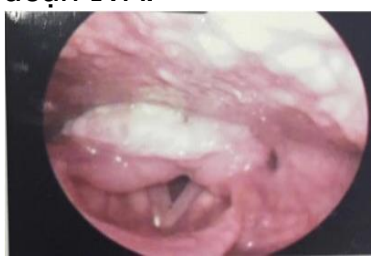

Thế sùi

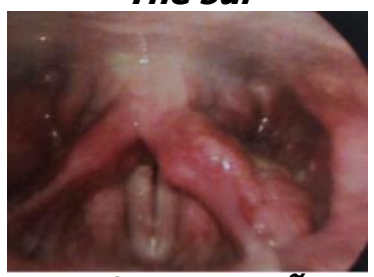

Thể thâm nhiễm

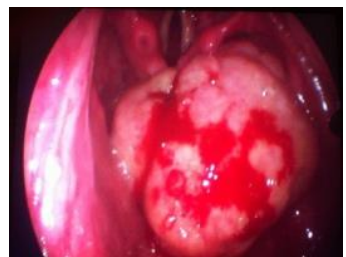

Thếloét

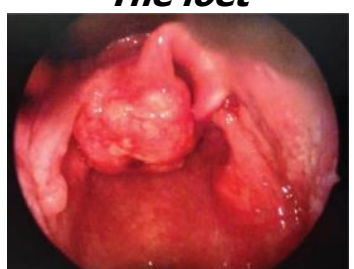

Thể hỗn hơp
Hình 4.1. Hinh thái khôi u qua nọi soi

Nhận xét: Các hình ảnh trong hình 4.1 được lấy qua nội soi tai mũi họng những người bệnh hiện còn điều trị tại bệnh viện. Hình thái u sùi bề ngoài giống như u nhú, một số trường hợp giống như polyp có cuống. Hình thái thâm nhiểm niêm mạc có vẻ nguyên vẹn, đôi khi có hình như núm vú, niêm mạc vùng này bị đây phồng lên và ít di động. Hình thái loét thường có bờ không đều, chạm vào dễ chảy máu. Thể hỗn hợp là thể vừa tăng sinh vừa loét, hoặc vừa loét vừa thâm nhiễm.
Bảng 4.2. Đặc điểm hình thái UTHH-TQ qua nội soi

\begin{tabular}{|c|c|c|}
\hline $\begin{array}{c}\text { Đặc điếm u qua } \\
\text { nội soi }\end{array}$ & Số lượng & Tỷ lệ \%o \\
\hline Vị trí u & & \\
Xoang lêt trái & 47 & 46,5 \\
Xoang lê phải & 35 & 34,7 \\
Vùng sau nhẫn & 9 & 8,9 \\
Thành sau họng & 8 & 7,9 \\
Thanh môn & 2 & 2 \\
\hline Hình thái u & & \\
Sùi & 70 & 69,3 \\
Hô̂n hợp & 19 & 18,8 \\
Thâm nhiễm & 10 & 9,9 \\
Loét & 2 & 2 \\
\hline
\end{tabular}

Nhân xét: Kết quả nghiên cứu cho thây hâu hết khối u hạ họng xuất phát từ xoang lê trong đó u xoang lê trái gặp nhiều hơn, vị trí thanh quản chỉ gặp 2 trường hợp nằm ở thanh môn. Về hình thái chủ yếu là thể sùi.

\section{BÀN LUÂN}

1. Một số đặc điểm lâm sàng, mô bệnh học

- Chì số toàn trạng (PS): Trong nghiên cứu này, người bệnh khi đến khám với chỉ số toàn trạng chủ yếu là $P S=1$ (64,4\% - Bảng 4.1). Kết quả này khác với Đàm Trọng Nghĩa (2018) nghiên cứu trên 41 người bệnh UTHH-TQ giai đoạn III-IV cho thấy chỉ số toàn trạng chủ yếu $\mathrm{PS}=0(73,2 \%)$, còn lại là $\mathrm{PS}=1$ [1]. Điều này được giải thích do đây là nghiên cứu mô tả cắt ngang, trong khi của Đàm Trọng Nghĩa là nghiên cứu can thiệp lâm sàng nên tác giả chủ đích lựa chọn những người bệnh chỉ số PS thấp, bằng 0 hoắc 1 để đảm bảo đủ sức khỏe nhằm chịu được quá trình điêu trị mạnh và kéo dài. Chỉ số toàn trạng là một yếu tố quan trọng giúp bác sĩ lựa chọn phác đồ điêu trị phù hợp, những người bệnh có chỉ số toàn trạng tốt thì ưu tiên lựa chọn phác đồ hóa chất bộ đôi hoặc kết hợp hóa xạ trị, ngược lại những người bệnh có chỉ số toàn trạng kém thì chỉ nên lựa chọn phác đô đơn chất hoặc chỉ chăm sóc triệu chứng đơn thuân là phù hợp.

- Đặc điểm mô bệnh học: Toàn bộ người bệnh trong nghiên cứu này thuộc thể ung thư biểu mô tế bào vảy (SCC), trong đó chủ yếu ở độ II (91\% - Bảng 4.1). Kết quả này tương đônng với các nghiên cứu ở Thái Lan và Việt Nam. Cụ thể, Pruegsanusak (2012) nghiên cứu 1186 người bệnh ung thư đâu cổ (trong đó có UTHHTQ) tai Thái Lan cũng cho thấy tỷ lê SCC đô II chiếm đa số [7]. Ở Việt Nam, Đàm Trọng Nghĩa (2018), Ngô Thanh Tùng (2011) cũng cho kết quả tương tự về phân độ mô học SCC [1] [3]. Sự biệt hóa các tế bào biểu mô vảy tỷ lệ nghịch với 
phát triển bệnh điều đó giải thích tỷ lê biệt hóa vừa và cao chiếm đa số trong các nghiên cứu ở người bệnh ung thư giai đoạn III, IV.

- Triệu chứng cơ nắng: Hầu hết người bênh trong nghiên cứu này có rối loạn nuốt ở các mức độ khác nhau (92,1\% - Bảng 4.1); tỷ lệ này cũng tương đương với tác giả Ranvida. Rối loạn nuốt là triệu chứng sớm, tiến triển tăng dần, giai đoạn đầu thường nhẹ, không liên tục nên người bệnh thường chủ quan dễ bỏ qua. Triệu chứng khó thở thanh quản 11,9\%, tương tự kết quả của Ravindra 11,8\%. Nổi hạch cổ ở nghiên cứu này là $73,3 \%$ cao hơn Ranvida $(45,1 \%)[8]$. Sự khác biệt này có thể do điều kiện kinh tế cũng như ý thức bảo vệ sức khỏe của người Việt Nam nói chung và người dân tỉnh Nghệ An nói riêng chưa cao, hầu hết chủ quan, $\mathrm{e}$ ngại đi khám bệnh, thường chờ đến khi xuất hiện các triệu chứng trên lâm sàng ảnh hưởng tới sinh hoat mới đi khám. Do đó đa số người bệnh khi vào viện đều đã có nổi hạch cổ. Qua đẩy cho thấy cần tăng cường công tác truyền thông cho người dân biết, đi khám sớm để phát hiện UTHH-TQ, đối với bác sĩ khám sức khỏe thì cần bắt buộc khám hạ họng và thanh quan cho mọi người dân tới khám sức khỏe.

Giai đoạn bệnh: Toàn bộ đối tượng trong nghiên cứu này đều ở giai đoạn III và IV, trong đó chủ yếu ở giai đoạn IV (69,3\% - Biểu đồ 4.1). Thực tế có nhiều nghiên cứu đã được tiến hành ở người bệnh UTHH-TQ giai đoạn muộn như Andreas Dietz và cs (2009), Lauren C (2014) cho thấy tỷ lệ ở giai đoạn IV chiếm chủ yếu từ 50 đến $76,7 \%$ [6] [5]. Như phân tích ở trên, sự hiểu biết cũng như ý thức chăm sóc sức khỏe của người dân chưa cao nên khi phát hiện bệnh, đa số đều ở giai đoạn muộn. Điều này ảnh hưởng rất lớn đến kết quả điều trị cũng như việc lựa chọn phương pháp điều trị ở giai đoạn muộn gặp nhiêu khó khăn thách thức. Vì vậy, bên cạnh việc công tác truyền thông nhằm nầng cao kiến thức về chuyên ngành ung bướu, cần tăng cường khám sàng lọc và tầm soát sức khỏe cho người dân, đặc biệt ở vùng sâu vùng xa, vùng dân tộc thiểu số để kịp thời phát hiện bênh khi còn ở giai đoạn sớm, mang lợi hiệu quả tích cực trong điều trị bệnh.

2. Đăcc điểm hình thái UTHH-TQ qua nội soi

- Vị trí u: Hầu hết khối u xuất phát từ xoang lê, còn lại 8,9\% xuất phát từ mặt sau sụn nhẫn, $7,9 \%$ từ thành sau họng (Bảng 4.2). Đối với những trường hợp u nguyên phát từ thanh quản, hầu hết người bênh đã được phẫu thuâtt trước đó hoặc u ở giai đoạn sớm (I, II), vì vậy chỉ gặp hai trường hợp u ở thanh môn (chiếm 2\%). Kết quả này tương đương với Phùng Thị Hòa (2020) cho thấy khối u xuất phát từ xoang lê $85,4 \%$; măt sau nhẫn và thành sau họng cùng chiếm $7,3 \%[4]$.

- Hình thái u: Trong nghiên cứu của này, hình thái sùi chiếm chủ yếu (69,3\% - Bảng 4.2). Kết quả này gần tương đồng với Nguyễn Như Ước (2019) có $65,6 \%$ ở thể sùi đơn thuân, $21,3 \%$ có kèm loét và thể hỗn hợp sùi loét hoại tử là $11,5 \%$ [3]. Theo Ngô Thanh Tùng, thể sùi chiếm $80 \%$, sùi kèm loét hoại tử là $11,5 \%$; thâm nhiễm có 3,3\%; loét đơn thuần 1,7\%[2]. Như vậy, các nghiên cứu đều cho thấy, UTHH-TQ có hình thái tổn thương chủ yếu là thể sùi.

\section{KẾT LUÂN}

Đặc điểm lâm sàng và mô bệnh học của UTHH-TQ

- Chỉ số toàn trạng chủ yếu là $P S=1$

- Mô bênh họ:: $100 \%$ SCC ở độ mô học II và III.

- Triệu chứng cơ năng thường gặp là rối loạn nuốt chiếm 92,1\%

- Giai đoạn bệnh chủ yếu ở giai đoạn IV chiếm $69,3 \%$

Đăc điểm hình thái UTHH-TQ qua nội soi

- UTTHH-TQ chủ yếu xuất phát từ xoang lê chiếm $81,2 \%$.

- Hình thái tổn thương chủ yếu của UTHHTQ là thể sùi chiếm 69,3\%.

\section{TÀI LIỆU THAM KHẢO}

1. Đàm Trong Nghĩa (2018). Nghiên cứu ứng dụng hóa trị trước phôi hợp hóa xạ trị đồng thời ung thư hạ họng thanh quản giai đoạn IIII-IV, Luận án tiến sĩ y học, Đại học Y Hà Nội, trang 53-56

2. Ngô Thanh Tuung (2011). Nighiên cứu một số đăc điểm lâm sàng, cân lâm sàng và kết quả hoá xạ trị gia tốc đồng thời ung thư hạ hong - thanh quản giai đoạn III - IVB không mố được tại Bệnh viện K2011, Luận án Tiến sỹ, Đại học Y Hà Nội.

3. Nguyê̂n Như Ước (2019). Nghiên cứu đăc điểm lâm sàng, cắt lớp vi tính và mối liên quan của một số yếu tố tiên lượng với kết quả điều trị của ung thư hạ họng, Luận án Tiến sỹ, Đại học Y Hà Nội, trang 49-51.

4. Phùng Thi Hòa (2020). Đánh giá điều trị ung thư biểu mô vảy hạ họng giai đoạn III, IV (MO) bằng Cisplatin - Taxane và $5 \mathrm{FU}$ trước phấu thuât và/hoăc xa trị, Luận án Tiến sỹ, Đại học Y Hà Nội, trang 51-52.

5. De Souza Viana $\mathbf{L}$, et al (2016). Efficacy and safety of a cisplatin and paclitaxel induction regimen followed by chemoradiotherapy for patients with locally advanced head and neck squamous cell carcinoma, Head Neck, 38(1), 970-980.

6. Dietz A, et al (2009). Induction chemotherapy with paclitaxel and cisplatin followed by radiotherapy for larynx organ preservation in advanced laryngeal and hypopharyngeal cancer offers moderate late toxicity 
outcome (DeLOS-I-trial), Eur. Arch. Oto-RhinoLaryngol. Off. J. Eur. Fed. Oto-Rhino-Laryngol. Soc. EUFOS Affil. Ger. Soc. Oto-Rhino-Laryngol. - Head Neck Surg, 266(8), 1291-1300

7. K. Pruegsanusak et al (2012)., Survival and prognostic factors of different sites of head and neck cancer: an analysis from Thailand', Asian Pac. J. Cancer Prev. APJCP, 13(3), 885-89.

8. Ravindra U và John B (2007)."Neoplasm of hypopharynx and cervical eosophagus". Cummings CW Otolaryngology, Elsevier, Philadelphia, USA.

\title{
NGHIÊN CỨU SỰ PHÂN BỐ CỦA CÁC CHỦNG S. AUREUS KHÁNG METHICILLIN (MRSA) VÀ NỒNG Độ ỨC CHẾ TỐI THIỂU CỦA VANCOMYCIN ĐỐI VỚI CÁC CHỬNG MRSA PHÂN LÂ̂P TẠI BỆNH VIỆN TRUNG ƯƠNG THÁI NGUYÊN
}

\author{
Nguyễn Thị Thu Thái ${ }^{1}$, Lương Thị Hồng Nhung ${ }^{1}$, \\ Nguyễn Thị Huyền ${ }^{2}$
}

\section{TÓM TẮT}

Vancomycin là kháng sinh hàng đâu được sử dụng cho nhiễm trùng do tụ cầu vàng kháng methicillin (MRSA). Tuy nhiên, sổ lượng ngày càng tăng các chủng MRSA có MIC cao mặc dù vấn trong phạm vi nhay cảm (vancomycin MIC "creep") có liên quan đến thất bai trong điều trị, đang được báo cáo trên toàn thế giới. Nghiên cứu này nhằm mục đích xác định nồng độ ức chế tối thiểu (MIC) của vancomycin đối với MRSA phân lập tại Bệnh viện Trung ương Thái Nguyên. Phương pháp: nghiên cứu mô tả cắt ngang trên 140 chủng S.aureus phân lập tịa Bệnh viện Trung ương Thái Nguyên từ tháng 1 đến tháng 12 năm 2020, xác định MRSA bằng kỹ thuật Kirby-Bauer, xác định MIC vancomycin của các chủng MRSA bằng kỹ thuât Etest. Kết quả: Hầu hết các chủng MRSA có khả năng kháng lại nhiều loại kháng sinh thông thường. Trong tổng số 140 chủng $\mathrm{S}$. aureus phân lập từ các loại bệnh phẩm khác nhau, tỷ lệ chủng MRSA là $61,43 \%$. Nồng đố ức chế tối thiêu của vancomycin trong khoảng $0.5 \mu \mathrm{g} / \mathrm{ml}$ đến $2 \mu \mathrm{g} / \mathrm{ml}$. Số chủng có MIC của vancomycin $1,5-2 \mu \mathrm{g} / \mathrm{ml}$ chiếm tỷ lệ $51,17 \%$. Hầu hết các chủng MRSA đều kháng lại các kháng sinh thông thường được sử dụng.

Tư khóa: S. aureus, MRSA, vancomycin.

\section{SUMMARY}

\section{DISTRIBUTION OF METHICILLIN-} RESISTANT S. AUREUS (MRSA) AND MINIMUM INHIBITORY CONCENTRATION OF VANCOMYCIN TO MRSA ISOLATED IN THAI NGUYEN CENTRAL HOSPITAL

Vancomycin, the first line antibiotic for methicillinresistant Staphylococcus aureus (MRSA). However, an increasing number of MRSA isolates with high MICs,

\section{${ }^{1}$ Trường Đại học Y Dược Thái Nguyên}

2Bệnh viện Trung ương Thái Nguyên

Chiu trách nhiêm chính: Nguyễn Thi Thu Thái

Email: thuthaitn@gmail.com

Ngày nhận bài: 18.01.2021

Ngày phản biện khoa học: 17.3.2021

Ngày duyệt bài: 25.3.2021 within the susceptible range (vancomycin MIC creep), are being reported worldwide. This study aims to determine the minimum inhibitory concentration (MIC) of vancomycin for MRSA at Thainguyen Central Hospital. Methods: Cross-sectional descriptive research. Collection of 140 MRSAs isolated infection at Thainguyen Central Hospital from 01/2020 to $12 / 2020$. Determination of MRSA by using the KirbyBauer disk-diffusion technique. MIC of vancomycin to confirmed MRSA strains were determined by Etest method. Results: A total of $140 \mathrm{~S}$. aureus isolates from different specimens in this study; MRSA rate is $61,43 \%$ (86 strains), Minimum inhibitory concentrations of vancomycin to the strains of MRSA ranged from $0.5 \mu \mathrm{g} / \mathrm{ml}$ to $2 \mu \mathrm{g} / \mathrm{ml}$. The number of strains with MIC of $1.5 \mu \mathrm{g} / \mathrm{ml}-2 \mu \mathrm{g} / \mathrm{ml}$ were 44 $(51,14 \%)$. Most of the MRSA strains were resistant against multiple classes of commonly used antibiotics.

Keywords; S. aureus, MRSA, vancomycin.

\section{I. ĐẶT VẤN ĐỀ}

Tụ cầu vàng (Staphylococcus aureus) là một trong những căn nguyên hàng đâu gây nhiễm trùng cộng đồng và nhiễm trùng bệnh viện, dẫn đến những hậu quả nghiêm trọng [1], [7], [8]. Hiện nay, hiện tượng $S$. aureus kháng kháng sinh trở nên khá phổ biến do tình trạng sử dụng kháng sinh ngày càng nhiều ở cộng đồng với những kháng sinh có hoạt phổ rộng, nhiều loại kháng sinh khác nhau với liều lượng chưa hợp lý. Vi khuẩn tụ cầu vàng kháng thuốc có thể gây ra các bệnh cảnh lâm sàng khác nhau và thường xuyên phân lập được trong các nhiễm trùng cộng đồng và nhiễm trùng bệnh viện. Tụ cầu vàng kháng methicilline (Methicillin-Resistant Staphylococcus aureus - MRSA) là một vấn đề $y$ tế toàn cầu, đang gia tăng về tân suất, hiện hữu ở nhiều cơ sở y tế và cộng đồng; gây khó khăn lớn cho việc điều trị [1], [7], [8].

Các kháng sinh Glycopeptide như vancomycin thường được sử dụng trong điều trị các chủng MRSA. Nhưng việc sử dụng rộng rãi vancomycin 